\title{
Residual ground-water levels of the neonicotinoid thiacloprid perturb chemosensing of Caenorhabditis elegans
}

\author{
Hannah Hopewell $^{1} \cdot$ Kieran G. Floyd $^{1} \cdot$ Daniel Burnell $^{1} \cdot$ John T. Hancock $^{1} \cdot$ \\ Joel Allainguillaume ${ }^{1} \cdot$ Michael R. Ladomery $^{1} \cdot \operatorname{Ian}$ D. Wilson $\mathbb{D}^{1}$
}

Accepted: 10 June 2017 / Published online: 22 June 2017

(C) The Author(s) 2017. This article is an open access publication

\begin{abstract}
This study investigated the neurological effects of residual ground-water levels of thiacloprid on the nontarget organism Caenorhabditis elegans. Nematodes treated with thiacloprid showed a dose-dependent and significantly increased twitch response at concentrations above $50 \mathrm{ng}$ $\mathrm{mL}^{-1}$ that disabled their forward locomotion in liquid culture. In comparison with untreated controls, $10 \mathrm{ng} \mathrm{mL} \mathrm{m}^{-1}$ thiacloprid perturbed the chemosensory ability of C. elegans such that the nematodes no longer demonstrated positive chemotaxis towards a $\mathrm{NaCl}$ chemo-attractant, reducing their chemotaxis index from +0.48 to near to zero. Nematodes also exhibited a locomotion characteristic of those devoid of chemo-attraction, making significantly more pirouetting turns of $\geq 90^{\circ}$ than the untreated controls. Compared to the untreated controls, expression of the endocytosis-associated gene, Rab-10, was also increased in C. elegans that had developed to adulthood in the presence of $10 \mathrm{ng} \mathrm{mL}^{-1}$ thiacloprid, suggesting their active engagement in increased recycling of affected cellular components, such as their nAChRs. Thus, even residual, low levels of this less potent neonicotinoid that may be found in field ground-water had measurable effects on a beneficial soil organism which may have environmental and ecological implications that are currently poorly understood.
\end{abstract}

Keywords Neonicotinoid $\cdot$ Thiacloprid $\cdot$ Chemosensing $\cdot$ Nematodes $\cdot$ Caenorhabditis elegans

Ian D. Wilson

ian2.wilson@uwe.ac.uk

1 Department of Applied Sciences, Faculty of Health and Applied Sciences, University of the West of England, Bristol, Frenchay Campus, Coldharbour Lane, Bristol BS16 1QY, UK

\section{Introduction}

Thiacloprid is a member of the neonicotinoid family of systemic insecticides which act as agonists of the postsynaptic ligand operated ion channels of the nervous system, the nicotinic acetylcholine receptors (nAChRs) (Matsuda et al. 2005, 2009). Irreversible binding of neonicotinoids to nAChRs induces muscular over-stimulation, paralysis and death (Yamamoto 1999; Vo et al. 2010; Easton and Goulson 2013). Unlike nicotine, the neonicotinoids are characterised by a common pharmacophore containing either a nitroimine, nitromethylene or cyanoimine group which confers, supposedly, selective toxicity because the specific amino acids of the loop structures of the ligand binding domains that enable interaction with these compounds are thought to be exclusively present in insect nAChRs (Tomizawa and Casida 2005). Agronomically, as systemic insecticides, neonicotinoids are usually applied as a seed dressing and are taken up during subsequent germination and growth, rendering the plant persistently toxic to any chewing or sucking insect.

In 2013 the European Food Safety Authority (EFSA) enforced a 2 year Europe wide ban on the use of the three neonicotinoids, imidacloprid, thiamethoxam and clothianidin because of their suspected involvement in bee colony collapse disorder. Several studies outlined the possible effects of these pesticides on bee populations as a result of exposure to contaminated pollen, nectar and dust from treated crops (Krupke et al. 2012; Blacquière et al. 2012; Sanchez-Bayo and Goka 2014). Exposure to neonicotinoids was shown to reduce queen survival rate and colony size and to disrupt the highly evolved navigational mechanisms employed by bees during their foraging and return to the hive (Fischer et al. 2014; Williams et al. 2015). Additionally, more recent concerns have been highlighted 
surrounding the effects of neonicotinoids on non-target, invertebrate organisms (Pisa et al. 2015).

Despite these concerns, thiacloprid escaped the ban due to its reported lower insect toxicity (Iwasa et al. 2004). However, other studies have suggested it may be more toxic to fish than many of the other neonicotinoids (Schmuck 2001). Thiacloprid is also considered one of the more persistent neonicotinoids in the environment. Since it does not absorb light beyond $290 \mathrm{~nm}$ (Peña et al. 2011), it is not readily subjected to sunlight-induced photolysis (Gupta et al. 2008) and with its chemical stability, may take considerable time to degrade in the environment (Černigoj et al. 2007). The half-life of thiacloprid is stated as being 19.1 days in soil, but may be considerably longer in anaerobic soils and it has been suggested that, with repeated use on water retentive soils, the groundwater residue concentrations of this neonicotinoid, as for imidacloprid, may similarly reach between 18 to $60 \mathrm{ng} \mathrm{mL}^{-1}$ depending on the application rate (Goulson 2013), which is within the range at which it could be toxic to susceptible organisms (LangerJaesrich et al. 2010). Consequently, this study investigated the effects of environmentally realistic levels of thiacloprid on the non-target, model organism Caenorhabditis elegans, a soil-borne nematode.

\section{Materials and methods}

\section{Growth, culturing and treatment of C. elegans with thiacloprid}

The Bristol N2 strain of C. elegans was gratefully received from Prof. Patricia Kuwabara at Bristol University, Bristol, $\mathrm{UK}$ and aseptically maintained at $21^{\circ} \mathrm{C}$ in the dark either on nematode growth media (NGM) agar plates spread with a lawn of the slow-growing, uracil auxotrophic Escherichia coli strain, OP50, as a food source or in shaking (20 rpm), liquid, M9 buffer culture, again using the same strain of $E$. coli as food (Stiernagle 2005). Thiacloprid $\left(\mathrm{C}_{10} \mathrm{H}_{9} \mathrm{ClN}_{4} \mathrm{~S}\right)$ was obtained from Sigma-Aldrich (PESTANAL analytical standard grade, suitable for HPLC and $>99.9 \%$ pure). In order to determine the immediate and short term physical effects of thiacloprid on $C$. elegans, nematodes were exposed for $1 \mathrm{~h}$ in liquid culture to a range of concentrations $\left(0.1 \mathrm{ng} \mathrm{mL}{ }^{-1}\right.$ to $\left.10 \mu \mathrm{g} \mathrm{mL}^{-1}\right)$ of the pesticide. To assess the effect of the pesticide on mortality, after the incubation period, individual treatments were scored for their kill percentage by counting the proportion of the nematodes that had attained the motionless, straightened, rod shape appearance which is characteristic of dead C. elegans in liquid media.

\section{Thiacloprid-induced twitch assays}

Mixed developmental stage populations of $C$. elegans were gently washed from NGM plates using $\mathrm{S}$ basal media (Stiernagle 2005) and using the same buffer throughout were washed three times by low speed centrifugation $\left(100 \times \mathrm{g}, 30 \mathrm{~s}, 21^{\circ} \mathrm{C}\right)$ to remove contaminating $E$. coli and were finally resuspended at 1000 nematodes $\mathrm{mL}^{-1}$. Replicate aliquots containing $50 \mathrm{C}$. elegans were then mixed in 96 well plates with buffer containing thiacloprid to give final volumes of $100 \mu \mathrm{L}$ with a range of thiacloprid concentrations between zero and $10 \mu \mathrm{g} \mathrm{mL}^{-1}$. Nematodes were incubated with the pesticide for $30 \mathrm{~min}$ at $21^{\circ} \mathrm{C}$ and their mortality and twitch movements were then observed under a binocular microscope and recorded using video capture at 20 frames $\mathrm{s}^{-1}$.

\section{Chemotaxis assays}

Replicate chemotaxis assays were performed according to Saeki et al. 2001 using $\mathrm{NaCl}$ as the chemo-attractant. Mixed developmental stage populations of $C$. elegans were collected from NGM plates as before and were treated in liquid culture $+/-10 \mathrm{ng} \mathrm{mL}^{-1}$ thiacloprid for $1 \mathrm{~h}$ at $21^{\circ} \mathrm{C}$ before their application to chemotaxis plates (Fig. 1). Replicate 8 $\mathrm{cm}$ diameter NGM agar plates were divided into three equal, wedge shaped zones and $\approx 150$ nematodes, both treated and untreated control, were placed in zone $\mathrm{A}$ and given the choice of migrating towards either a $\mathrm{NaCl}$ attractant spot in zone B or a control spot in zone C. Both the control and attractant spots also contained a small amount of $\mathrm{NaN}_{3}$, applied as $1 \mu \mathrm{L}$ of a $0.5 \mathrm{M}$ solution just before plates were used, which effectively immobilised the nematodes that reached either position.

Nematodes were allowed to migrate for $1 \mathrm{~h}$ at $21^{\circ} \mathrm{C}$ on the plates before their positions were recorded using a binocular microscope. Chemotaxis indices were then calculated as described (Saeki et al. 2001). Chemotaxis plates were also photographed after the $1 \mathrm{~h}$ migration in order to visualise the tracks left by individual $C$. elegans and the number of pirouetting turns of $\geq 90^{\circ}$ that had been made by the nematodes was recorded.

\section{Developmental synchronisation of $C$. elegans}

Eggs were collected from adult hermaphrodite $C$. elegans according to Stiernagle (2005) and were hatched on NGM agar plates without a food source. Hatched larvae were thus, maintained at $21^{\circ} \mathrm{C}$ for $24 \mathrm{~h}$ to allow their synchronous development to the L1 stage before their transfer to $E$. coli OP50 NGM agar plates $+/-10 \mathrm{ng} \mathrm{mL}^{-1}$ thiacloprid. Larvae were then allowed to develop for a further $48 \mathrm{~h}$ to young adult stage, were washed from plates using $\mathrm{S}$-basal buffer as 

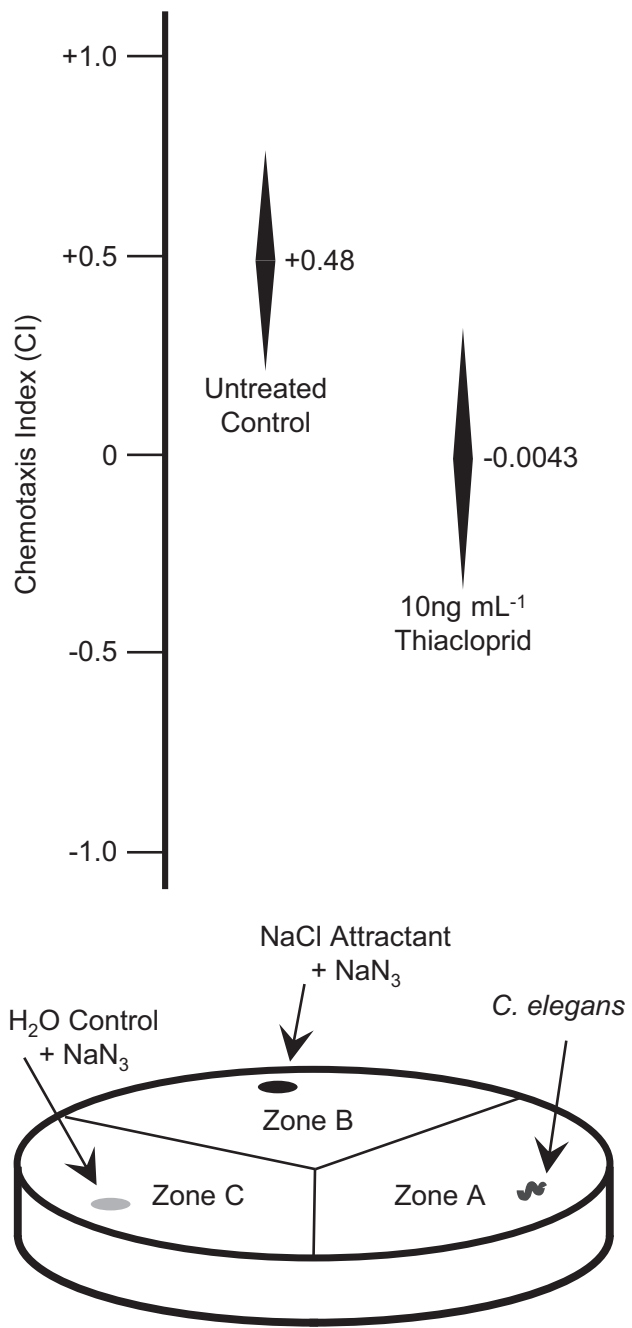

Fig. 1 Thiacloprid altered the chemosensing of $\mathrm{NaCl}$ by C. elegans. Six replicate samples of mixed growth stage populations of $\approx 150 \mathrm{C}$. elegans $\left(\mathrm{N}_{\text {total }}\right)$ were treated $+/-10 \mathrm{ng} \mathrm{mL}^{-1}$ thiacloprid for $1 \mathrm{~h}$ at $21^{\circ} \mathrm{C}$ in $\mathrm{S}$ basal buffer before being applied to zone A of individual chemotaxis plates (represented above). The nematodes were allowed to migrate on the plates for a further $1 \mathrm{~h}$ before the numbers present in each zone were counted under a microscope. The mean numbers of the nematodes present in zones $\mathrm{B}$ and $\mathrm{C}\left(\mathrm{N}_{\mathrm{B}}\right.$ and $\left.\mathrm{N}_{\mathrm{C}}\right)$ along with the corresponding $95 \%$ confidence intervals $(95 \%$ Conf. Int.) around the means were calculated in each case. Significant differences $(P<0.05)$, or not $(P>0.05)$, in the numbers of nematodes migrating to each zone were determined by one way ANOVA and the chemotaxis index (CI) ranges shown were then calculated at the $95 \%$ confidence level using the formula $C I=\left(N_{B}-N_{C}\right) / N_{\text {total. }}$. Thus, the upper CI value of each range arose from $\left[\left(\mathrm{N}_{\mathrm{B}}+95 \%\right.\right.$ Conf. Int. $)-\left(\mathrm{N}_{\mathrm{C}}-95 \%\right.$ Conf. Int. $\left.)\right] /$ $\mathrm{N}_{\text {total }}$ and the lower CI value from $\left[\left(\mathrm{N}_{\mathrm{B}}-95 \%\right.\right.$ Conf. Int. $)-\left(\mathrm{N}_{\mathrm{C}}+\right.$ 95\% Conf. Int.)] $/ \mathrm{N}_{\text {total }}$. The mid-point $\mathrm{CI}$ values are indicated in each case

before and subsequently purified away from contaminating E. Coli by centrifugal flotation on a $30 \%$ (w/v) sucrose density cushion (Stiernagle 2005). The nematodes were aspirated from the top of the sucrose cushion and were washed with an excess of buffer, pelleted by centrifugation and the pellets were immediately frozen in liquid nitrogen.

\section{RT-PCR analysis}

According to the manufacturer's instructions, total RNA was extracted from individual frozen pellets of $C$. elegans using TRI Reagent ${ }^{\circledR}$ (Sigma-Aldrich, UK) and was subsequently treated with DNaseI (Ambion $®$, Thermo Fisher Scientific, UK) to remove contaminating gDNA.

In final vols. of $20 \mu \mathrm{L}$ and using the buffer supplied, individual $8 \mu \mathrm{g}$ aliquots of the DNase-treated total RNA samples were subjected to anchored oligo-(dT) $)_{18}(0.5 \mu \mathrm{g})$ primed reverse transcription for $90 \mathrm{~min}$ at $42{ }^{\circ} \mathrm{C}$ using 400 units of SuperScript ${ }^{\circledR}$ II reverse transcriptase (Thermo Fisher Scientific, UK) in the presence of $500 \mu \mathrm{M}$ dNTPs, $5 \mathrm{mM}$ DTT and 20 units of SUPERase $-\mathrm{In}^{\mathrm{TM}}$ RNase inhibitor (Thermo Fisher Scientific, UK). The reactions were subsequently heat inactivated at $65^{\circ} \mathrm{C}$ for $15 \mathrm{~min}$ and the resulting cDNA solutions diluted 1 in 100 with SDW before their use in PCR analysis.

Using the buffer supplied, PCR reactions $\left(10 \mathrm{~min}\right.$ at $95^{\circ}$ $\mathrm{C}$, then 35 cycles of $1 \mathrm{~min}$ at $95^{\circ} \mathrm{C}, 1 \mathrm{~min}$ at $55^{\circ} \mathrm{C}, 1 \mathrm{~min}$ at $72{ }^{\circ} \mathrm{C}$ and finally $15 \mathrm{~min}$ at $72{ }^{\circ} \mathrm{C}$ ) were performed in a final vol. of $25 \mu \mathrm{L}$ containing $10 \mu \mathrm{L}$ of diluted cDNA template and 2.5 units of MyTaq ${ }^{\text {TM }}$ HS DNA Polymerase (Bioline, UK) in the presence of $2.5 \mu \mathrm{M}$ forward and reverse DNA oligonucleotide primers and $500 \mu \mathrm{M}$ dNTPs. Gene specific DNA oligonucleotide primer sets used for PCR amplification were: Ama-1 (Forward 5'-CAGTGGCTCATGTCGAGT-3', Reverse 5'-CGACCTTCTTTCCATCAT-3'); Ced-4 (Forward 5'-TCGACGAGATGTGTGATTTAG-3', Reverse 5'-GTTTTCGGTTCACAAGACTTG-3') (Shaham and Horvitz 1996); Rab-10 (Forward 5'CGAGTTGTGAGCAGAGAACG-3', Reverse 5'CCTCTGTGGTTGCACTGGATTCACC-3'). Following amplification, PCR products were separated by electrophoresis alongside DNA size markers (Bioline, UK) in $1 \times$ TAE $1.5 \%$ (w/v) agarose gels containing $1 \mu \mathrm{g} \mathrm{mL}{ }^{-1} \mathrm{EtBr}$ and were visualised under UV illumination.

\section{Data analysis and bioinformatics}

Where appropriate, data were assessed for normality and between data group heteroscedasticity by Shapiro-Wilk and Bartlett's tests. Data were then analysed for overall treatment effect by using either one way ANOVA or KruskalWallis tests depending on their parametric adherence or not. Post hoc significant differences between the means of groups were then determined by either 2-sample $t$ tests, Tukey-Kramer tests or by Dunn's test. In all cases statistically significant differences were determined at the $95 \%$ confidence level $(P<0.05$ that the null-hypothesis was acceptable).

The blastp alogorithm (Altschul et al. 1990) was used to search the non-redundant protein sequences database at the 
National Centre for Biotechnology Information (NCBI) to identify sequences from other neonicotinoid-susceptible species that were highly similar to that of the neurotransmitter-gated ion-channel ligand binding domain found between residues 23 to 229 of the full length amino acid sequence of the $C$. elegans nAChR- $\alpha 16 \mathrm{~A}$ subunit (NP_505207). Multiple sequence alignments were performed using Clustal Omega (Sievers et al. 2011) at the European Molecular Biology Laboratory, European Bioinformatics Institute (EMBL-EBI) (Goujon et al. 2010) and neighbour joining phylogenetic tree analysis of aligned sequences was performed using Paup 4.0b10 (Swofford 2002).

\section{Results}

\section{Thiacloprid altered the motility of $C$. elegans}

Based on the experience with the neonicotinoid imidacloprid, in which repeated applications of the pesticide have been shown to result in ground-water levels of 18-60 ng mL $\mathrm{mL}^{-1}$ (Goulson 2013), we decided to test a wide range of concentrations of thiacloprid upwards from $0.1 \mathrm{ng} \mathrm{mL}{ }^{-1}$. Over the range of concentrations used there was no significant difference in the apparent mortality of the nematodes during the incubation period (data not shown). However, while the lower concentrations of thiacloprid appeared to have no immediate effect on the movement of the nematodes, those above $100 \mathrm{ng} \mathrm{mL}^{-1}$ caused a noticeable and significant increase in the rate of twitching of the nematodes compared to that of those in the untreated controls (Fig. 2) and also exaggerated the extent of the twitch movement itself. In the control $\mathrm{S}$ basal liquid cultures used here, individual C. elegans achieved forward locomotion by oscillating the full length of their bodies from side to side in apparent twitching movements at the rate of approximately $40 \mathrm{~min}^{-1}$. Here, a single twitch involved the nematodes progressing from a relatively straight body position through a curled position with head and tail in lateral proximity, followed by a subsequent return to a straight body appearance. Successive twitches involved the nematodes curling in the opposite direction to that of the immediately preceding twitch. At relatively high concentrations, between 0.5 to $10 \mu \mathrm{g} \mathrm{mL}^{-1}$, thiacloprid increased the rate of twitching of the nematodes to between approximately 75 to $155 \mathrm{~min}^{-1}$ respectively and also exaggerated the severity of the actual twitch movement so that the heads and tails of the nematodes became crossed at the height of the movement. At thiacloprid concentrations of $\geq 5 \mu \mathrm{gL}^{-1}$ forward movement of the nematodes also effectively ceased as they rapidly curled and uncurled in the same relative position.

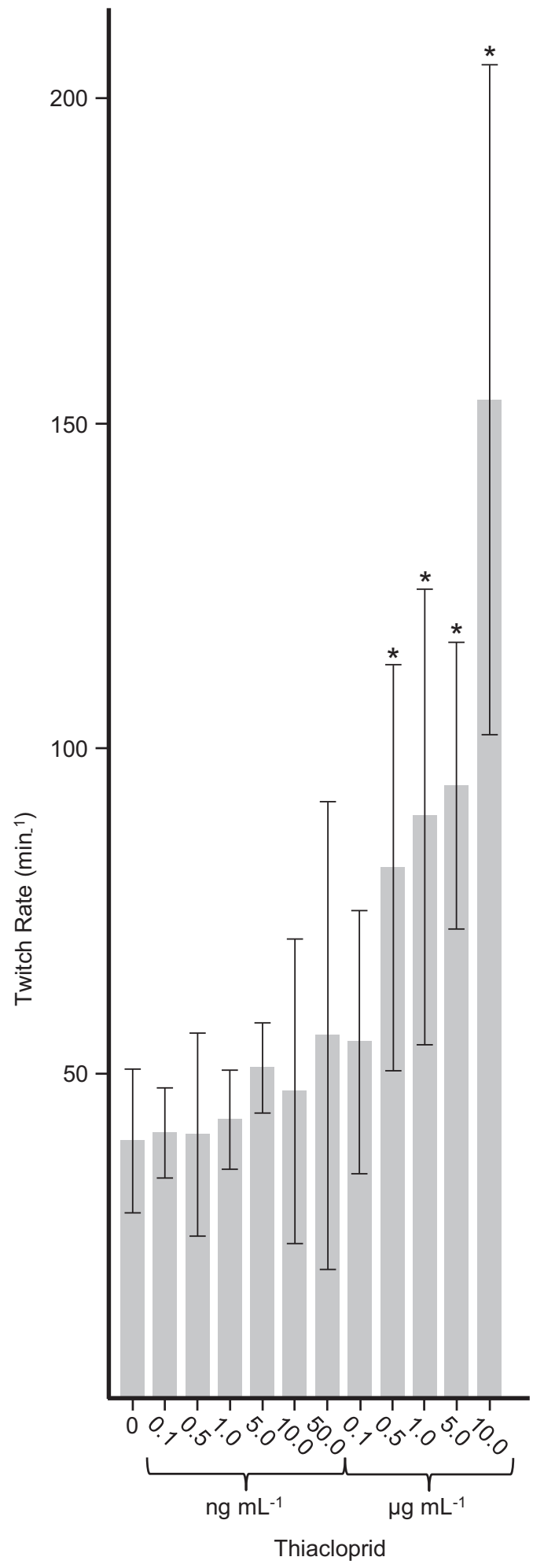


Fig. 2 Elevated levels of thiacloprid induced an increased twitch response in $C$. elegans. Replicate $(n=3)$ experimental samples (50 nematodes per sample) of mixed growth stage populations of C. elegans suspended in $\mathrm{S}$ basal buffer were exposed to a range of concentrations of thiacloprid and in each case, the mean rates of twitching of the 150 individual nematodes were monitored under a microscope using video capture at 20 frames $\mathrm{s}^{-1}$. Results are presented as the mean twitch rate with errors shown as the $95 \%$ confidence intervals around the means for each concentration of thiacloprid used. *Indicates a twitch rate significantly increased above that of the control $(P<0.05$ by Dunn's test $)$

\section{Thiacloprid altered $\mathrm{NaCl}$ chemo-sensing by $C$. elegans}

Although concentrations of thiacloprid below $100 \mathrm{ng} \mathrm{mL}^{-1}$ did not appear to significantly alter the movement behaviour of C. elegans, its neurotoxic mode of action necessitated a more sensitive appraisal of its effects on the nematodes. One way to determine the extent of neurological perturbations in $C$. elegans is to monitor their ability to undertake chemotaxis towards a chemo-attractant, such as $\mathrm{NaCl}$. Typically, such assays are routinely performed on agar plates divided into three or more zones. The nematodes, treated or otherwise, are applied to one zone and given free range to migrate towards other zones on the chemotaxis plate which may contain either different or competing chemo-attractants or which may operate as control zones.

Before their application to separate plates, replicate aliquots of $C$. elegans were treated $+/-10 \mathrm{ng} \mathrm{mL}^{-1}$ thiacloprid for $1 \mathrm{~h}$ in liquid culture. This level of thiacloprid was chosen because it did not induce a significant increase in nematode twitching (Fig. 2) that may have potentially hampered their movement on the plates, but was a concentration that might be expected to occur in the groundwater of soils following the agronomic application of the pesticide. After application, the treated and untreated nematodes were allowed to migrate on the chemotaxis plates for $1 \mathrm{~h}$, at which time the numbers in each zone were counted. In either case approximately $50 \%$ of the $C$. elegans migrated out of zone $\mathrm{A}$ and into either zone $\mathrm{B}$ or $\mathrm{C}$. In the assays the mean number of nematodes migrating towards the $\mathrm{NaCl}$ attractant in zone $\mathrm{B}$ was consistently and significantly $(P<0.05$ by one way ANOVA and 2 sample $\mathrm{t}$ test) higher when using the untreated control nematodes as compared to when those treated with thiacloprid were applied to the chemotaxis plates. Once this had been determined, for both thiacloprid-treated and untreated nematodes replicate chemotaxis assay measurements were then used to calculate chemotaxis index mid-point and range values at the $95 \%$ confidence level (Fig. 1). The midpoint chemotaxis index of +0.48 for the untreated control group of nematodes indicated that in the absence of thiacloprid the majority of the nematodes that migrated out of zone $\mathrm{A}$ were attracted to and moved towards the $\mathrm{NaCl}$ spot in zone B. For the nematodes treated with $10 \mathrm{ng} \mathrm{mL}^{-1}$ thiacloprid the mid-point chemotaxis index of -0.0043 indicated that the pesticide treatment had effectively negated the ability of the nematodes to discern and respond to the presence of the $\mathrm{NaCl}$ attractant, such that their choice of direction of movement became considerably more random.

\section{Thiacloprid treatment of $C$. elegans prevented normal feeding-associated locomotion during $\mathrm{NaCl}$ chemosensing}

When placed on agar plates, in the absence of an attractant, such as either a food source or $\mathrm{NaCl}, C$. elegans demonstrate a pirouetting behaviour during their locomotion where they make frequent turns of $\geq 90^{\circ}$ and thus, overall, appear to move in a directionless and random manner. However, once a positive chemo-attractant has been detected, the nematodes generally move along the chemical stimulus gradient, make fewer turns of this magnitude and thus, overall, appear to move in a determined direction towards the attractant.

Here, during the migration of the thiacloprid-treated and untreated nematodes across separate $\mathrm{NaCl}$ chemotaxis plates the movement tracks made by the $C$. elegans during the $1 \mathrm{~h}$ incubation period were recorded photographically. In each case the mean number of turns of $\geq 90^{\circ}$ made by the nematodes was determined and is shown in Fig. 3. Nematodes exposed to $10 \mathrm{ng} \mathrm{mL}^{-1}$ thiacloprid for $1 \mathrm{~h}$ subsequently exhibited a significantly higher mean number of turns of this magnitude when placed on chemotaxis plates using a $\mathrm{NaCl}$ spot as the attractant, effectively performing 6 times more pirouettes than those of the untreated control groups. Thus, the indication is that the thiacloprid treatment effectively prevented the nematodes from perceiving the chemo-attractant and thus, from moving in a determined direction towards the source of the potential attraction.

\section{Sequence conservation of the ligand binding domains of the nAChRs of neonicotinoid-susceptible species}

Neonicotinoids effect their action through binding to the ligand binding domains of the neuronal nicotinic acetylcholine receptors (nAChRs) of susceptible species. Since C. elegans was obviously affected by thiacloprid, Clustal Omega amino acid sequence alignment and Paup 4 phylogenetic analyses were performed using the amino acid sequence of the ligand binding domain of its nAChR- $\alpha 16 \mathrm{~A}$ subunit and those of the most similar nAChR subunits identified for a number of other neonicotinoid-susceptible species by Blastp searching of the non-redundant sequences database at the NCBI (Figs. 4 and 5). Insects, fish, annelid worms and other nematodes have all previously been shown 


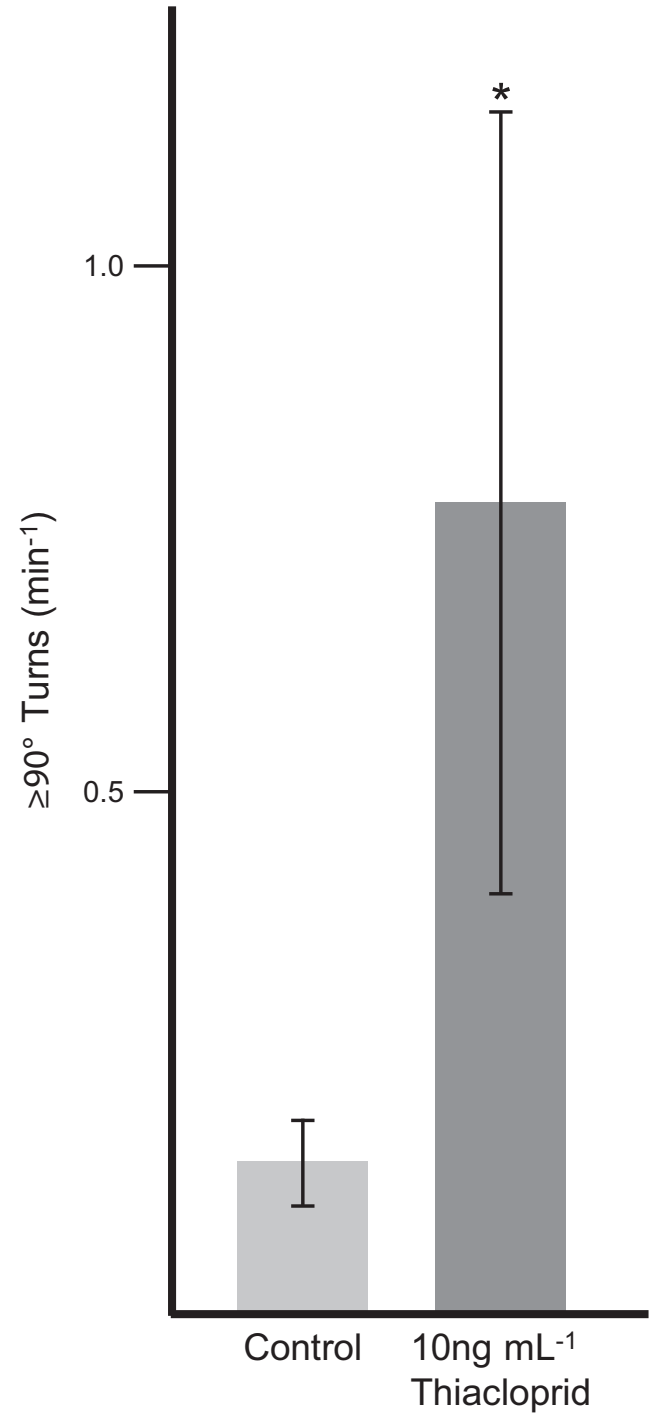

Fig. 3 Thiacloprid altered the pirouetting behaviour of $C$. elegans during salt chemosensing. Six replicate samples of mixed growth stage populations of $\approx 150 \mathrm{C}$. elegans were treated $+/-10 \mathrm{ng} \mathrm{mL}^{-1}$ thiacloprid for $1 \mathrm{~h}$ at $21^{\circ} \mathrm{C}$ in $\mathrm{S}$ basal buffer before being applied to individual chemotaxis plates. During their subsequent $1 \mathrm{~h}$ migration on the plates the nematodes left visible tracks which were recorded photographically and the total number of turns of $\geq 90^{\circ}$ which were made during the incubation period were recorded. The results are presented as the mean number of such turns made $\min ^{-1}$ with the errors shown as the $95 \%$ confidence intervals around the calculated means in each case. *Indicates a significant difference in the rate of turning compared to the control ( $P<0.05$ by Dunn's test)

to be susceptible to neonicotinoids and comparison of the amino acid sequences of the ligand binding domains of the identified $\mathrm{nAChR}$ subunits indicated a high degree of phylogentic conservation between $C$. elegans and these species, especially in the amino acids considered to be involved in the binding of thiacloprid to insect nAChRs, as indicated by the arrows shown in Fig. 4 .
Development of $C$. elegans in the presence of thiacloprid increased expression of genes involved in apoptosis and cell secretion

Treatments that induce aberrant neural responses in $C$. elegans have previously been shown to be accompanied by neurodegeneration and increased neural apoptosis and cell secretion as a result of upregulated endocytic recycling (Wang and Audhya 2014). Thus, in order to determine if such processes resulted in C. elegans following their exposure to groundwater levels of thiacloprid, duplicate populations of developmentally synchronised nematodes were allowed to develop to the young adult stage in the presence of a bacterial food source $+/-10 \mathrm{ng} \mathrm{mL}^{-1}$ thiacloprid and the expression of the genes Cell death 4 (Ced-4) and Ras-related protein 10 (Rab-10) was investigated by RT-PCR (Fig. 6). Expression of the constitutively expressed gene encoding RNA polymerase II (Ama-l) was also determined as a cDNA synthesis control to show both technical and RT consistency throughout.

While the expression of Ama- 1 appeared consistent throughout the experiment, the expression of Rab-10 appeared to be greatly increased in the nematodes that had been cultured to young adult stage in the presence of 10 $\mathrm{ng} \mathrm{mL}{ }^{-1}$ thiacloprid. In the same $C$. elegans cultures, Ced-4 expression was apparent at reasonable levels in both the untreated and thiacloprid-treated nematodes, but showed a marginal increase in those cultured in the presence of the neonicotinoid.

\section{Discussion}

We observed that $10 \mathrm{ng} \mathrm{mL}^{-1}$ thiacloprid caused sufficient hyper-stimulation of the chemosensory neurons of the nematodes to the extent that they effectively chemo-sensed equally regardless of whichever direction they turned. In contrast with the untreated controls, the increased pirouetting of the nematodes, their random direction of movement and their inability to migrate positively towards the $\mathrm{NaCl}$ chemo-attractant after thiacloprid exposure was highly indicative of hyper-stimulation. C. elegans sense their environment primarily by using their amphid chemosensory organs, which contain eleven pairs of chemosensory neurons (Bargmann 2006). Proper functioning of these neurological pathways is important if the nematodes are to appropriately respond to chemosensory cues which, depending on the signal, can elicit chemotaxis, rapid avoidance, changes in overall motility and entry into and exit from the alternative, starvation-associated, stationary, dauer developmental stage.

Increased endocytic recycling in C. elegans is a process associated with numerous disease states, including 
Fig. 4 Clustal Omega amino acid sequence alignment of the ligand binding domains of neuronal nicotinic acetylcholine receptors (nAChRs) from thiacloprid-susceptible species. The Blastp alogorithm was used to identify amino acid sequences from the representative species indicated [(a) P. dumerilii (ACI88788), (b) C. teleta (ELU07054), (d) H. contortus (ABW07339), (e) O. niloticus (XP_003450802), (f) H. burtoni (XP_005930510), (g) D. rerio (AAI62599), (h) H. rubusta (ESN90492), (i) M. domestica (ABY40460), (j) A. Melifera (XP_006559134), (k) D. melanogaster (NP_001260302)] that showed a high degree of similarity to that of (c), the ligand-binding domain of the $C$. elegans nAChR- $\alpha 16$ A subunit (NP_505207). The identified sequences were aligned using the multi-alignment programme Clustal Omega at EMBL-EBI. Invariant ${ }^{(*)}$ amino acids are highlighted in orange and substituted (. or:) amino acids in green. Arrows indicate the amino acids thought to be involved in thiacloprid binding to the nAChRs of the honey bee (A. melifera) by either hydrogen bonding or hydrophobic interaction (Selvam et al. 2014)
HKK LHD L- - YQKGVRPVRNESTVINVVVRITIHQIRELDEKNQFIVTNVWIRFF R 81 -ERI IGD FRGAE $Y H H L S R$ REEMDALDVQFAITI Q I IEVDEKNEMLHTNMWLNY I 103 ERR YED M--RN $Y N N L E R$ PVANHSEPVTVHLKVALQ I IDVDEKNQVVYVNAWLDYTWN 80 ERR YED M--RD YNSLERPVANHSKPVTVYLKVSLQ QI IDVDEKNQIVHVNAWLDYTWK 79 QRRIYSDIM--NG NPLVRPVQNDSQSLIVSFGLTIMQIMDVDEKNQVLTTNIWLQLYWT 83 QRRI YSD M--NG YNPLVRPVQNDSQSLIVSFGLTIM IMDVDEKNQVLTT IWLQLY T 83 QRRI YRD M- KD NPLERPVFNDTHSLTVYFSMSTM IMDVDEKNOVLTT IWLQLY Y 83 EKRILNT FADGA NKLER PVADDKEPLIVNFSLTLQ I IDVDEKNQIIHTNLWLNIKN 81 EKRILHD L--DT NTIIR RPVNESDPLQLSFGLTIMIIDVDEKNQLLVTNVWLKLE N 339 EKR LNE LL--SS NTLERPVANESEPLEVKFGITLQ IDVDEKNQILTTNAWLKLE $N 110$ EKRILNH L-ST $\triangle N T L E R P V A N E S E P L E V K F G L T L Q I I D V D E K N Q I L T T N A W L N L E N \quad 87$

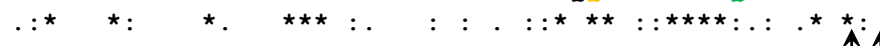<smiles>C1CC1C1CC2CC21</smiles>

Loop D

EF $\triangle$ Q NPED YGGITRMHV SSLVWQ $Q$ IVLYNS DQNALAKD FMSDTNVEVSPD NMSW 141 DK S WNETE YGGVS IRL SKLIWT DILLYNRTQQFS---NFCVHQFRMQGR CCVS 160 YN $\triangle$ VWKAE YNITDVRF PAGKIWK PDVLLYNS DTNFD---STYQTNMIVYST $G$ LVHW 137 DYK VWDVSE YGNITDVRF PAGRIWK DVLLYNS DTNFD---STYPTNMVVYST DVHW 136 DYY Q WNPLD PGVSNVRF DHLIWK DILLYNS DERFD---ATFRTNILVNSS TCSY 140 $\triangle Y Y \perp Q N$ NLD Y PGVSNVRF PDHLIWK DILLYNS DERFD---ATFRTNILVNSS TCSY 140 DYY QWNASEYPGVTNVRF PDSIWK DILLYNS DERFD---ATFHTNVLVNSS ACQY 140 $D$ YN $\triangle W N P Q E$ VNISSLRI SANHIWR D ILMYNS DEDID---STFPTNIVVSSN $\triangle N C L W 138$ MN R RNTSD YGGIKDLRI P PHRIWK PDVLMYN S DEGFD---GTYQTNVVVRNN SCLY 396 YN Q WNESE YGGVKDLRIT PNKLWK D ILMYNS DEGFD---GTYQTNVVVTHN SCLY 167 DN R RNETE YGGVKDLRIT PNKLW KDVLMYN S DEGFD---GTYHTNIVVKHN SCLY 144 * * *: : $*: \quad::$<smiles>CC(C)C1CC(C)C1C</smiles><smiles>[C]1CCC1C1CC1</smiles>

\section{Loop A}

TAPALLKSSCMIKIQDYPFDKQTCKLKLGSWTYNGWEINISYFA-PEILTDNYIPDGEWE 200 GPVSLS---FSSYDEWFR-GLIKCSLKFGSWTYDGNKINLTQSN-DFIDLDTYQAS GEWE 215 VPPGIFKISCKIDIQWFPFDEQKCFFKFGSWTYDGYKLDLQPAT-GGFDISEYISNGEWA 196 VPPGIFKIS KIDIEWFSFDEQRCKFKFGSWTYDGFKLDLQPAK-KGFDISEYLPNGEWT 195 LPPGIFKSTCHIDVRWFPFDVQRCDLKFGSWTYGGWSLDLKVMD---ADISNYIANGEWD 197 LPPGIFKSTCHIDVRWF PFDVQR DLKFGSWTYGGWSLDLKVMD---ADISNYIANGEWD 197 LPPGIFKSTCYIDVRWFPFDLQRCDLKFGSWTYGGWSLDLQMID---ADITGYIANGEWD 197 VPPGMFASTCKIDISWFPFDDQRCKMKFGSWTYDSSGINLILQNDT-GDVSNFIPSGEWD 197 VPPGIFKSTCKIDITWFPFDDORCEMKFGSWTYDGFOLDLQLODETGGDISSYVLN GEWE 456 VPPGIFKSTCKIDITWFPFDDQHCDMKFGSWTYDGNQVDLVLSSETGGDLSDFITNGEWY 227 VPPGIFKSTCKIDITWFPFDDQHCEMKFGSWTYDGNQLDLVLNSEDGGDLSDFITNGEWY 204

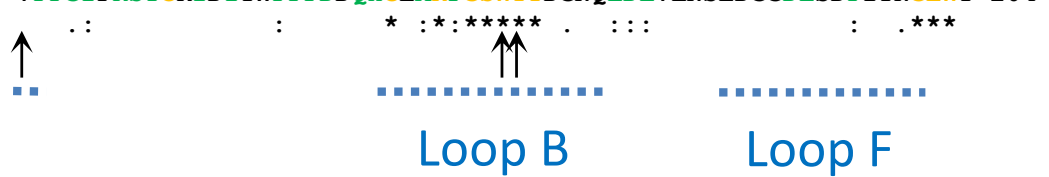

ILDAPCERNEVFYSCCPOPFPDVTCYLKLKRL- 232 IIDVPAVRNVKT QCCPEPYIDITFTIHIRRR- 247 LPLTTVER EKF DCCPEPYPDVHFYLHMRRRA 229 LPLTTVSRNVKF DCCPEPYPDLTFYLHMRRR- 227 LVEVPGQRNEHF GCCEEPYPDVTFTVVMRRR- 229 LVEVPGQR EHF GCCEEPYPDVTFTVVMRRR- 229 LVEVPGRR ERF DCCKEPYPDVTFTVVMRRR- 229 LIGMPASRNVLS DCCPEQYIDITFVIHIRRR- 229 LLGVPGKRNEIY NCCPEPYIDITFAIIIRRR- 488 LIGMPGKKNTIT QCCPEPYVDVTFTIQIRRR- 259 LLAMPGKKNTIV ACCPEPYVDITFTIQIRRR- 236

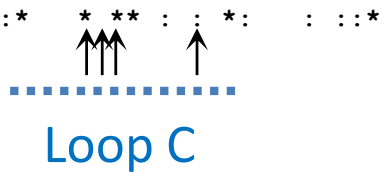

(a)

(b)

(c)

(d)

(e)

(f)

(g)

(h)

(i)

(j)

(k) 


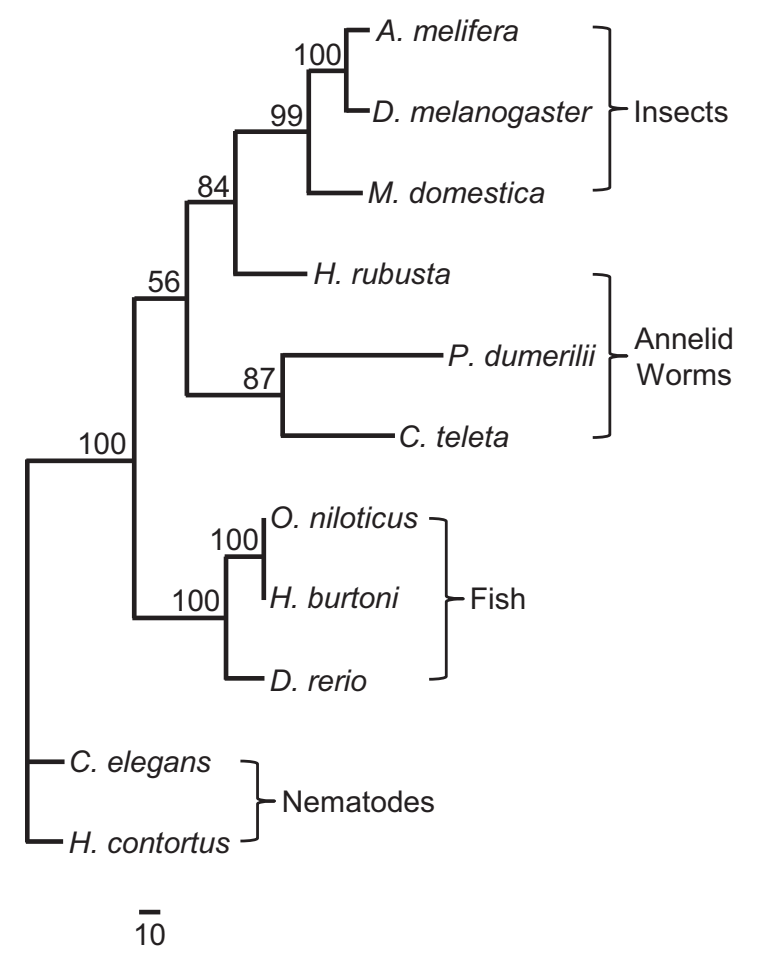

Fig. 5 Neighbour joining phylogenetic tree analysis of the ligand binding domain amino acid sequences of neuronal nicotinic acetylcholine receptors (nACRs) from thiacloprid-susceptible species. The BlastP alogorithm was used to identify amino acid sequences from the representative species indicated [A. melifera (XP_006559134), D. melanogaster (NP_001260302), $M$. domestica (ABY40460), $H$. rubusta (ESN90492), P. dumerilii (ACI88788), C. teleta (ELU07054), O. niloticus (XP_003450802), H. burtoni (XP_005930510), D. rerio (AAI62599), H. contortus (ABW07339)] that showed a high degree of similarity to that of the ligand binding domain of the $C$. elegans nAChR- $\alpha 16$ A subunit (NP_505207). Phylogenetic tree construction using the identified sequences was performed using Paup 4.0b10 (Swofford 2002). Bootstrap values after 1000 replicates are shown as percentages and the scale bar indicates the fraction of substitutions per amino acid site

neurodegeneration (Wang and Audhya 2014). Previous studies have shown a marked increase in the number of recycling endosomes during the onset of apoptotic neurodegeneration in $C$. elegans, evidenced by an increase in Rab-11 expression (Troulinaki and Tavernarakis 2012), a GTPase that performs a similar role in endocytosis to that of Rab-10. Here, although the level of expression of the apoptosis-associated gene, $\mathrm{Ced}-4$, showed only a marginal increase in the nematodes cultured to adult stage in the presence of thiacloprid, the very marked increase in the level of expression of $R a b-10$ was indicative of enhanced endocytic processes that may have been associated with neurological dysfunction. The low level of thiacloprid used here was sufficiently toxic to enhance endocytic recycling in an attempt to replace dysfunctional nAChRs.

The argument that neonicotinoids, such as thiacloprid, are selectively toxic towards insects because of differences

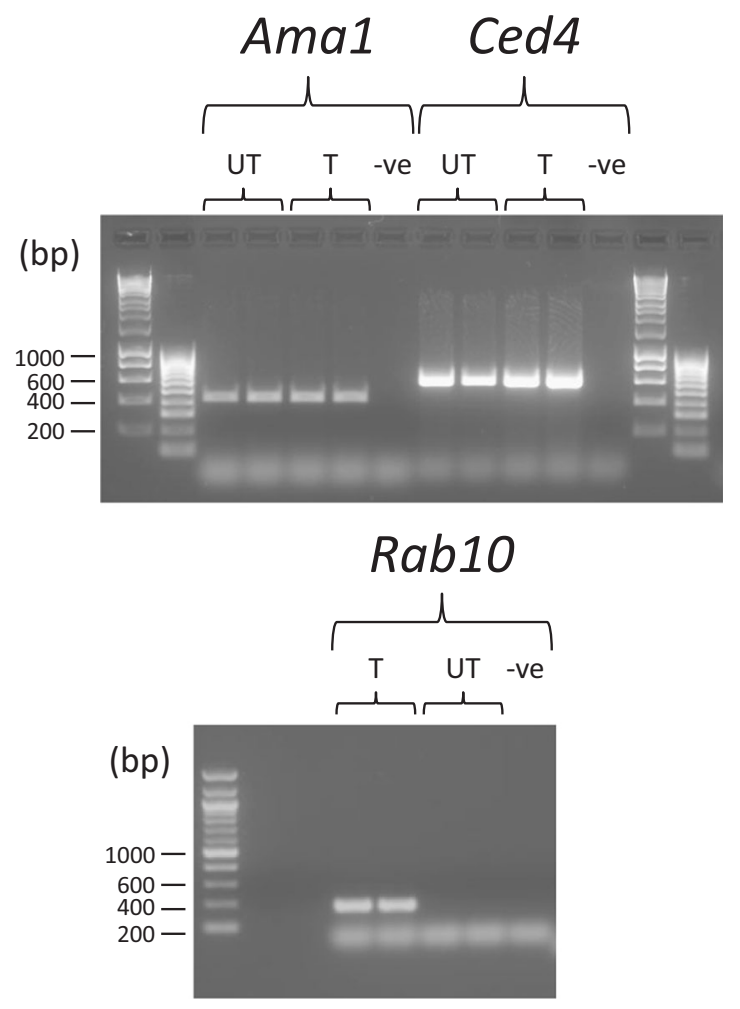

Fig. 6 Accumulation of mRNAs encoding cell death and secretion related proteins in $C$. elegans following their exposure to the neonicotinoid pesticide, thiacloprid. Multiple thousands of $C$. elegans eggs were hatched on NGM plates in the absence of food and allowed to developmentally synchronise to L1 stage larvae for $24 \mathrm{~h}$. Synchronised L1 larvae were then transferred en masse to E. coli OP50 lawns on NGM agar plates $+/-10 \mathrm{ng} \mathrm{mL}^{-1}$ thiacloprid (UT-untreated; T-treated) and were allowed to develop at $21^{\circ} \mathrm{C}$ to young adult stage, at which point total RNA was extracted and $8 \mu \mathrm{g}$ aliquots were subjected to RT-PCR analysis with gene specific primers designed to amplify regions of the coding sequences for the proteins RNA polymerase I (Ama-1), Cell death protein 4 (Ced-4) and Ras-related protein 10 (Rab-10). Shown are the PCR products of duplicate experiments visualised by $\mathrm{UV} / \mathrm{EtBr}$ staining after their electrophoresis in agarose gels alongside DNA size markers

in the structure of their nAChRs may hold true when comparisons are made with mammals (Tomizawa and Casida 2005; Liu et al. 2010). However, it is fairly clear from this study that such an argument is less applicable when comparing insect nAChRs with those from other nonmammalian, neonicotinoid susceptible species. Phylogenetically, insects, annelid worms, fish and nematodes appear to separate into distinct clades when comparing the amino acid sequences of the ligand binding domains of their nAChRs, with the nematodes being furthest away from the insects in this comparison. However, the phylogenetic distances between the groups in the comparison presented here are not large and simple multiple sequence alignment showed how similar this domain is between these species and that, in the comparison made, there was crucially a high degree of conservation of the amino acids thought to be 
involved in binding of thiacloprid to the receptors of insects, such as the honey bee (Selvam et al. 2014). Neonicotinoids have previously been shown to be toxic to all the other species used to compare with $C$. elegans in this study (Gibbons et al. 2015).

Soil fauna such as nematodes play an important role as detrivores, recycling nutrients from the bacterial biomass (Bongers and Bongers 1998) in a manner that has been shown to be beneficial to plant growth (Ferris et al. 2012). Disrupting the chemosensory ability of such organisms may then have implications for soil ecology that impact negatively on agricultural practices that use organic matter as a source of plant nutrition. In our study, nematodes were provided with an abundance of bacterial food and realistically did not have to search for it. Thus, at the low level of thiacloprid used, development of the nematodes from L1 to the adult stage appeared to be visibly unaffected. However, it is less clear whether or not this would be the case in a field situation where the nematodes had to employ their chemosensory ability to find such food. Certainly, the feeding behaviour of other soil organisms, such as earthworms, has been shown to be negatively affected by the application of neonicotinoids in a field environment (Lal et al. 2001; Dittbrenner et al. 2010). C. elegans also use their chemosensory ability to avoid potentially harmful environments and to decide whether or not to enter the resting, dauer developmental stage in times of food deprivation. Should residual levels of neonicotinoids in the soil perturb such processes it would seem inevitable that some negative impact on nematode populations would occur as a consequence.

The neonicotinoid class of pesticides became available in the early 1990s with the commercial release of imidacloprid and because of the ease of their agronomic deployment, cost efficiency and their selectivity in controlling insect pests, they saw a rapid rise in their use worldwide. By 2010 neonicotinoids had attained a $26 \%$ share of the global market (Casida and Durkin 2013) with some 1.2 million hectares of crops being treated with neonicotinoids in the UK alone (Easton and Goulson 2013). Thiacloprid was released for agronomic use in 2000 (Elbert et al. 2000) and with its three orders of magnitude higher $\mathrm{LD}_{50}$ of $14.6 \mu \mathrm{g}$ per bee, as compared to $18 \mathrm{ng}$ per bee for imidacloprid (Iwasa et al. 2004), it escaped the temporary ban imposed on the use of other more potent neonicotinoids by the EFSA in 2013, which was enforced in order to allow time for research concerning their possible involvement in bee colony collapse disorder. While there is substantial evidence, well reviewed by Van der Sluijs et al. (2013), that neonicotinoids are harmful to bee populations, there has been far less consideration given to the wider off-target effects of these pesticides, in particular with regard to the potentially harmful effects of the less potent neonicotinoids on non- insect, invertebrate species. Here, the results presented indicated that relatively low levels of one of the less toxic neonicotinoids, thiacloprid, at sub-lethal concentrations that may be expected to occur in groundwater run-off, had potentially detrimental effects on the chemosensory ability of the soil nematode, $C$. elegans. It is thus, an ecological imperative that groundwater concentrations of even this less toxic neonicotinoid are not permitted to increase beyond those already apparent and it would be appropriate to investigate further the long term ecological impact of its use in the field.

\section{Conclusions}

The environmental and ecological impact of the widely used neonicotinoid insecticides is currently poorly understood. This paper adds to growing evidence that their use may have persistent, unforeseen effects on non-target organisms. Here, specifically, thiacloprid was seen to impede the ability of $C$. elegans to engage in positive chemotaxis which coincided with a significant change in their normal locomotion characteristics.

Acknowledgements We would like to thank Dr Carrie Brady for her kind assistance with the phylogenetic analysis presented in this study and Debbie Lewis and Katy Hayward for their technical assistance in the laboratory. The funding for this research work was provided by the University of the West of England, Bristol, UK.

\section{Compliance with ethical standards}

Conflict of interest The authors declare that they have no competing interests.

Ethical approval This article does not contain any studies with human participants performed by any of the authors. All applicable international, national, and/or institutional guidelines for the care and use of animals (C. elegans) were followed.

Open Access This article is distributed under the terms of the Creative Commons Attribution 4.0 International License (http://crea tivecommons.org/licenses/by/4.0/), which permits unrestricted use, distribution, and reproduction in any medium, provided you give appropriate credit to the original author(s) and the source, provide a link to the Creative Commons license, and indicate if changes were made.

\section{References}

Altschul SF, Gish W, Miller W, Myers EW, Lipman DJ (1990) Basic local alignment search tool. J Mol Biol 215:403-410

Bargmann CI (2006) Chemosensation in C. elegans, Worm Book, ed. The C. elegans Research Community, WormBook. http://www. wormbook.org 
Blacquière T, Smagghe G, van Gestel CA, Mommaerts V (2012) Neonicotinoids in bees: a review on concentrations, side-effects and risk assessment. Ecotoxicology 21:973-992

Bongers T, Bongers M (1998) Functional diversity of nematodes. App Soil Ecol 10:239-251

Casida JE, Durkin KA (2013) Neuroactive insecticides: targets, selectivity, resistance, and secondary effects. Ann Rev Entomol 58:99-117

Černigoj U, Lavrenčič Štangar U, Trebše P (2007) Degradation of neonicotinoid insecticides by different advanced oxidation processes and studying the effect of ozone on $\mathrm{TiO}_{2}$ photocatalysis. App Catalysis B: Env 75:229-238

Dittbrenner N, Triebskorn R, Moser I, Capowiez Y (2010) Physiological and behavioural effects of imidacloprid on two ecologically relevant earthworm species (Lumbricus terrestris and Aporrectodea caliginosa). Ecotoxicology 19:1567-1573

Easton AH, Goulson D (2013) The neonicotinoid insecticide imidacloprid repels pollinating flies and beetles at field-realistic concentrations. PloS One 8:e54819

Elbert A, Erdelen C, Kuhnhold J, Nauen R, Schidt HW, Hattori Y (2000) Thiacloprid, a novel neonicotinoid insecticide for foliar application. BCPC Conf Pests Dis 1:21-26

Ferris H, Griffiths BS, Porazinska DL, Powers TO, Wang K-H, Tenuta M (2012) Reflections on plant and soil nematode ecology: past, present and future. Nematology 44:115-126

Fischer J, Müller T, Spatz AK, Greggers U, Grünewald B, Menzel R (2014) Neonicotinoids interfere with specific components of navigation in honeybees. PLoS One 9:e91364

Gibbons D, Morrissey C, Mineau P (2015) A review of the direct and indirect effects of neonicotinoids and fipronil on vertebrate wildlife. Environ Sci Pollut Res Int 22:103-118

Goujon M, McWilliam H, Li W, Valentin F, Squizzato S, Paern J, Lopez R (2010) A new bioinformatics analysis tools framework at EMBL-EBI. Nucl Acids Res 38(Suppl):W695-W699

Goulson D (2013) An overview of the environmental risks posed by neonicotinoid insecticides. J App Ecol 50:977-987

Gupta S, Gajbhiye VT, Gupta RK (2008) Effect of light on the degradation of two neonicotinoids viz acetamiprid and thiacloprid in soil. Bull Env Cont Toxicol 81:185-189

Iwasa T, Motoyama N, Ambrose JT, Roe RM (2004) Mechanism for the differential toxicity of neonicotinoid insecticides in the honey bee, Apis mellifera. Crop Prot 23:371-378

Krupke CH, Hunt GJ, Eitzer BD, Andino G, Given K (2012) Multiple routes of pesticide exposure for honey bees living near agricultural fields. PLoS One 7:e29268

Lal OP, Palta RK, Srivastava YNS (2001) Impact of imidacloprid and carbofuran on earthworm castings in okra field. Ann Plant Prot Sci 9:137-138

Langer-Jaesrich M, Köhler H-R, Gerhardt A (2010) Assessing toxicity of the insecticide thiacloprid on chironomus riparius (Insecta: Diptera) using multiple end points. Arch Environ Contam Toxicol 58:963-972

Liu GY, Ju XL, Cheng J (2010) Selectivity of imidacloprid for fruit fly versus rat nicotinic acetylcholine receptors by molecular modeling. J Mol Mod 16:993-1002

Matsuda K, Kanaoka S, Akamatsu M, Sattelle DB (2009) Diverse actions and target-site selectivity of neonicotinoids: structural insights. Mol Pharmacol 76:1-10

Matsuda K, Shimomura M, Ihara M, Akamatsu M, Sattelle DB (2005) Neonicotinoids show selective and diverse actions on their nicotinic receptor targets: electrophysiology, molecular biology, and receptor modeling studies. Biosci Biotechnol Biochem 69:1442-1452

Peña A, Rodríguez-Liébana JA, Mingorance MD (2011) Persistence of two neonicotinoid insecticides in wastewater, and in aqueous solutions of surfactants and dissolved organic matter. Chemosphere 84:464-470

Pisa LW, Amaral-Rogers V, Belzunces LP, Bonmatin JM, Downs CA, Goulson D, Kreutzweiser DP, Krupke C, Liess M, McField M, Morrissey CA, Noome DA, Settele J, Simon-Delso N, Stark JD, Van der Sluijs JP, Van Dyck H, Wiemers M (2015) Effects of neonicotinoids and fipronil on non-target invertebrates. Environ Sci Pollut Res Int 22:68-102

Saeki S, Yamamoto M, Iino Y (2001) Plasticity of chemotaxis revealed by paired presentation of a chemoattractant and starvation in the nematode Caenorhabditis elegans. J Exp Biol 204:1757-1764

Sanchez-Bayo F, Goka K (2014) Pesticide residues and bees-a risk assessment. PLoS One 9:e94482

Schmuck R (2001) Ecotoxicological profile of the insecticide thiacloprid. Pflanzenschutz Nachrichten-Bayer-English Ed 54:161-184

Selvam B, Gratona J, Laurenta AD, Alamiddinea Z, Mathé-Allainmata M, Lebretona J, Coqueret O, Olivierb C, Thanyc SH, Le Questela J-Y (2014) Imidacloprid and thiacloprid neonicotinoids bind more favourably to cockroach than to honeybee $\alpha 6$ nicotinic acetylcholine receptor: insights from computational studies. J Mol Graph Mod 55:1-12

Shaham S, Horvitz HR (1996) An alternatively spliced C. elegans ced4 RNA encodes a novel cell death inhibitor. Cell 86:201-208

Sievers F, Wilm A, Dineen DG, Gibson TJ, Karplus K, Li W, Lopez R, McWilliam H, Remmert M, Söding J, Thompson JD, Higgins D (2011) Fast, scalable generation of high-quality protein multiple sequence alignments using Clustal Omega. Mol Sys Biol 7:539

Stiernagle T (2005) WormBook, ed. The C. elegans Research Community, WormBook, http://www.wormbook.org

Swofford DL (2002) Phylogenetic analysis using parsimony (and other methods). Sinauer Associates, Sunderland, MA, Ver. 4

Tomizawa M, Casida JE (2005) Neonicotinoid insecticide technology: mechanisms of selective action. Ann Rev Pharmacol Toxicol 45:247-268

Troulinaki K, Tavernarakis N (2012) Endocytosis and intracellular trafficking contribute to necrotic neurodegeneration in C. elegans. EMBO J 31:176-181

Van der Sluijs J, Simon-Delso N, Goulson D, Maxim L, Bonmatin JM, Belzunces LP (2013) Neonicotinoids, bee disorders and the sustainability of pollinator services. Curr Op Env Sustainability 5:293-305

Vo DT, Hsu WH, Abu-Basha EA, Martin RJ (2010) Insect nicotinic acetylcholine receptor agonists as flea adulticides in small animals. J Vet Pharmacol Ther 33:315-322

Wang L, Audhya A (2014) In vivo imaging of $C$. elegans endocytosis. Methods 68:518-528

Williams GR, Troxler A, Retschnig G, Yañez O, Shutler D, Neumann P, Gauthier L (2015) Neonicotinoid pesticides severely affect honey bee queens. Sci Rep 5:14621

Yamamoto I (1999) Nicotine to nicotinoids: 1962 to 1997. In: Yamamoto I, Casida J (ed) Nicotinoid insecticides and the nicotinic acetylcholine receptor. Springer, Tokyo, p 3-27 